\title{
Análise da formação de educadores do Assentamento Paulo César Vinha a partir dos conceitos de vivência e experiência de Walter Benjamin e Jorge Larrosa Bondía
}

Analisys of the formation of educators of the Paulo César Vinha Settlement taking as a reference the concepts of isolated experiencie and long experience by Walter Benjamin and Jorge Larrosa Bondía Júlio de Souza Santos

Resumo: O presente estudo objetiva caracterizar as experiências de formação de educadores das modalidades da Educação de Jovens e Adultos e da Educação do Campo, na Escola Córrego do Cedro, do Assentamento Paulo César Vinha, que está vinculado ao Movimento dos Trabalhadores Rurais Sem Terra (MST) e situado no município de Conceição da Barra, na região Norte do Estado do Espírito Santo. Tomando como referência os conceitos de vivência e experiência, de Walter Benjamin e Jorge Larrosa Bondía; e de formação num sentido amplo, na perspectiva de Edna Castro de Oliveira, a pesquisa se beneficiou do aporte metodológico da Observação Participante com oito educadores de jovens e adultos. Considerando as concepções teórico-metodológicas adotadas, constatou-se, por um lado, um cenário de empobrecimento das experiências dos educadores, com o predomínio da vivência e, por outro lado, a existência de raras experiências dos educadores no contexto do Assentamento Paulo César Vinha.

Palavras-chave: Experiência. Formação. Educação de Jovens e Adultos. Educação do Campo.

Abstract: This study aims to characterize the training experiences of educators in the modalities of Youth and Adult Education and Field Education, at the Córrego do Cedro School, from the Paulo César Vinha Settlement, which is linked to the Movimento dos Trabalhadores Rurais Sem Terra (MST) [Movement of Landless Rural Workers] and located in the municipality of Conceição da Barra, in the Northern region of the State of Espírito Santo. Taking as a reference the concepts of isolated experience and long experience, by Walter Benjamin and Jorge Larrosa Bondía; and formation in a broad sense, from the perspective of Edna Castro de Oliveira, the research benefited from the methodological contribution of Participant Observation with eight youth and adult educators. Considering the theoretical-methodological concepts adopted, it was found, on the one hand, a scenario of impoverishment of the educators' experiences, with the predominance of the isolated experience and, on the other hand, the existence of rare long experiences of the educators in the context of the Paulo César Vinha Settlement.

Keywords: Experience. Formation. Youth and Adult Education. Field Education.

\section{Introdução}

Esse texto tem como objetivo caracterizar as experiências de formação de educadores, considerando as suas "trajetórias" de vida e a atuação docente nas modalidades da Educação de Jovens e Adultos (EJA) e da Educação do Campo, na Escola Córrego do Cedro, do Assentamento Paulo César Vinha, que 
está vinculado ao Movimento dos Trabalhadores Rurais Sem Terra (MST) e situado no município de Conceição da Barra, na região norte do Estado do Espírito Santo.

No contexto brasileiro, constata-se que os estudos sobre formação de educadores nos âmbitos da educação de jovens e adultos e da educação do campo são fundamentados predominantemente na concepção restrita de formação, que a reduz à formação inicial e à formação continuada, com ênfase na problemática das implicações da ausência dessas experiências formativas nas práticas educativas desenvolvidas nessas modalidades da educação básica.

Como contraponto a essa perspectiva reducionista da formação, Oliveira (2005) explora a concepção de formação num sentido amplo, denominada de poética de formação, não restrita às concepções de formação inicial e continuada, ao analisar as experiências de formação de educadores do MST.

Desse modo, na perspectiva de abordar os processos formativos de educadores do Assentamento Paulo César Vinha, a partir de uma concepção ampla de formação, essa exposição explorou a seguinte problemática: Como se caracterizam as experiências de formação de educadores de jovens e adultos do Assentamento Paulo César Vinha, considerando as suas "trajetórias de vida" e a atuação docente nas modalidades de EJA e da Educação do Campo?

Nesta tarefa, lanço mão de aportes teóricos que exploram os conceitos de vivência e experiência, de Walter Benjamin e Jorge Larrosa Bondía; e de poética de formação, na perspectiva de Edna Castro de Oliveira. Em seguida, o percurso metodológico da observação participante é explicitado em seus vários momentos, e, por fim, resultados são apresentados sobre as experiências de formação de educadores do Assentamento Paulo César Vinha.

\section{Os conceitos de vivência, experiência e formação}

"Em nossos livros de leitura havia a parábola de um velho que no momento da morte revela a seus filhos a existência de um tesouro enterrado em seus vinhedos. Os filhos cavam, mas não descobrem qualquer vestígio do tesouro enterrado em seus vinhedos. Com a chegada do outono, as vinhas produzem 
mais que qualquer outra na região. Só então compreenderam que o pai lhes havia transmitido uma certa experiência: a felicidade não está no ouro, mas no trabalho".

Walter Benjamin

No percurso de desenvolvimento do estudo, o conceito de experiência, na perspectiva do filósofo judeu alemão Walter Benjamin (1989; 1994), emergiu inicialmente como categoria de análise apropriada na caracterização das experiências de formação de educadores do Assentamento Paulo César Vinha.

Benjamin (1989) realiza a distinção entre vivência e experiência. O conceito de "vivência" refere-se à "experiência" vivida solitariamente pelo indivíduo isolado, enquanto a experiência propriamente dita é coletiva e se funda na arte de narrar, sendo transmitida de pessoa para pessoa. Na abordagem dessa diferenciação realizada por Benjamin, Konder (1999) destaca:

[...] O nosso crítico distinguia entre duas modalidades de conhecimento, indicadas por duas palavras diversas em alemão: Erfahrung e Erlebnis. "Erfahrung" e o conhecimento obtido através de uma experiência que se acumula, que se prolonga, que se desdobra, como numa viagem (e viajar, em alemão, é fahren); O sujeito integrado numa comunidade dispõe de critérios que lhe permitem ir sedimentando as coisas, com o tempo. "Erlebnis" é a vivencia do indivíduo privado, isolado; é a impressão forte, que precisa ser assimilada às pressas, que produz efeitos imediatos [...] (p.83).

No aprofundamento dessa oposição conceitual, Benjamin delimita que a experiência diz respeito ao mundo das tradições, em que o tempo era o da totalidade, enquanto a vivência consiste na experiência de caráter pessoal e individual, característica do mundo moderno (GONÇALVES, 2015).

A partir dos conceitos de vivência (Erlebnis) e experiência (Erfahrung), Benjamin (1994) afirma que a sociedade moderna é marcada pelo fenômeno do empobrecimento da experiência comunicável, apontando como uma das causas as experiências desmoralizadoras da guerra, da inflação, do corpo pela fome, moral dos governantes.

$\mathrm{Na}$ condição de contemporâneo da geração do período entreguerras, Benjamin (1994) destaca o silêncio dos combatentes vindos dos campos de 
batalha da Primeira Guerra Mundial (então Grande Guerra) para exemplificar a pobreza de experiência da modernidade:

[...] está claro que as ações da experiência estão em baixa, e isso numa geração que entre 1914 e 1918 viveu uma das mais terríveis experiências da história. Talvez isso não seja tão estranho como parece. Na época, já se podia notar que os combatentes tinham voltado silenciosos do campo de batalha. Mais pobres em experiências comunicáveis, e não mais ricos [...] (p.114-115).

Dessa forma, Benjamin (1994) afirma que as experiências estão em baixa e, consequentemente, a arte de narrar está em vias de extinção, pois as pessoas não sabem narrar devidamente, como se estivessem privadas da faculdade de intercambiar experiências.

Para Benjamin (1994), a verdadeira narrativa, que traz em si uma dimensão utilitária, seja num ensinamento moral, seja numa sugestão prática, seja num provérbio ou numa norma de vida, sintetizados no saber dar conselho, parece algo de antiquado em virtude das experiências estarem deixando de ser comunicáveis.

Nessa toada, é importante destacar que, apesar de não se extinguirem completamente, as experiências caminham para o desaparecimento completo, caracterizando-se como "sintoma de decadência" do período moderno (BENJAMIN, 1994).

Para Benjamin (1994), a figura do narrador torna-se tangível com a presença de dois grupos: o primeiro grupo consiste naquele que vem de longe, ou seja, aquele que viaja e tem muito a contar; o segundo grupo é formado por aqueles que ganharam honestamente sua vida sem sair do país e conhecem suas histórias e tradições. O primeiro grupo é exemplificado pelo marinheiro comerciante e o segundo grupo pelo camponês sedentário.

$\mathrm{Na}$ abordagem das causas do processo de enfraquecimento, destruição e decadência das experiências comunicáveis, Benjamin (1994) afirma que a informação passou a ser a principal ameaça à narrativa, a partir da consolidação da burguesia, para a qual a imprensa, no alto capitalismo, é um dos instrumentos mais importantes. 
Ao discorrer sobre a incompatibilidade entre narrativa e informação, Benjamin (1994) afirma:

O saber, que vinha de longe - do longe espacial das terras estranhas, ou do longe temporal contido na tradição -, dispunha de uma autoridade que era válida mesmo que não fosse controlável pela experiência. Mas a informação aspira a uma verificação imediata. Antes de mais nada, ela precisa ser compreensível "em si e para si". Muitas vezes não é mais exata que os relatos antigos. Porém, enquanto esses relatos recorriam ao miraculoso, é indispensável que essa informação seja plausível (p. 202-203).

Nesse contexto, o processo de difusão de informação, através da divulgação de fatos acompanhados de explicação, é a razão de sermos pobres em histórias surpreendentes. De acordo com Benjamin (1994, p. 203): "[...] quase nada do que acontece está a serviço da narrativa, e quase tudo está a serviço da informação. Metade da narrativa está em evitar explicações [...]". Segundo Orlante e Salinas (2015):

A indústria da informação não exige de um narrador que sustente o relato, mas apenas a exposição do fato em si, sem o mínimo emprego daquelas mediações, próprias ao contador de histórias, nas quais a sugestão pode fluir como um recurso típico, fazendo com que o ouvinte ou leitor fique preso ao relato (p. 213-214).

Esse processo de enfraquecimento da experiência no contexto contemporâneo, em virtude do excesso de informação, é enfatizado por Bondía (2002):

A informação não é experiência. E mais, a informação não deixa lugar para a experiência, ela é quase o contrário da experiência, quase uma antiexperiência. Por isso a ênfase contemporânea na informação, em estar informados, e toda a retórica destinada a constituir-nos como sujeitos informantes e informados; a informação não faz outra coisa que cancelar nossas possibilidades de experiência. O sujeito da informação sabe muitas coisas, passa seu tempo buscando informação, o que mais o preocupa é não ter bastante informação; cada vez sabe mais, cada vez está melhor informado, porém, com essa obsessão pela informação e pelo saber (mas saber não no sentido de "sabedoria", mas no sentido de "estar informado"), o que consegue é que nada lhe aconteça (p. 21-22). 
Para Bondía (2002, p.21), "a experiência é o que nos passa, o que nos acontece, o que nos toca. Não o que se passa, não o que acontece, ou o que toca". Além disso, esse autor destaca que nunca se passaram tantas coisas, enquanto a experiência é cada vez mais rara, corroborando com Walter Benjamin.

Além da informação, Bondía (2002) aponta que, em segundo lugar, a experiência é cada vez mais rara pelo excesso de opinião supostamente pessoal, própria e crítica sobre tudo aquilo que tem informação, convertendo-se em um imperativo.

Em terceiro lugar, Bondía (2002) aponta que a falta de tempo é responsável pela raridade da experiência:

Tudo o que se passa, passa demasiadamente depressa, cada vez mais depressa. $E$ com isso se reduz o estímulo fugaz e instantâneo, imediatamente substituído por outro estímulo ou por outra excitação igualmente fugaz e efêmera. $O$ acontecimento nos é dado na forma de choque, do estímulo, da sensação pura, na forma da vivência instantânea, pontual e fragmentada. A velocidade com que nos são dados os acontecimentos e a obsessão pela novidade, pelo novo, que caracteriza o mundo moderno, impedem a conexão significativa entre acontecimentos. Impedem também a memória, já que cada acontecimento é imediatamente substituído por outro que igualmente nos excita por um momento, mas sem deixar qualquer vestígio (p. 23).

Dessa forma, além de se caracterizar como alguém que está informado e opina, o sujeito moderno é um consumidor voraz e insaciável de notícias e de novidades, porém eternamente insatisfeito (BONDÍA, 2002).

Além do excesso de informação, do excesso de opinião e da falta de tempo, Bondía (2002) afirma que a experiência é cada vez mais rara em virtude do excesso de trabalho. Nessa perspectiva, o sujeito moderno acredita que pode fazer tudo o que se propõe, ou seja, está sempre em atividade e, para tanto, não duvida em destruir tudo o que se apresenta como obstáculo à sua onipotência.

Desse modo, apesar de apresentarem cenários distópicos, Walter Benjamin e Jorge Larrosa Bondía apresentam, cada qual em suas perspectivas teóricas e contextos vividos, dimensões importantes para um movimento de ressignificação desse processo de decadência da modernidade, como a 
caracterização das causas do empobrecimento das experiências e as condições para a existência da experiência e do narrador.

Considerando que o estudo se propõe a caracterizar as experiências de formação de educadores, emergiu a necessidade de relacionar o conceito de experiência com um conceito de formação numa perspectiva ampla, denominada de poética de formação, que concebe o sujeito da experiência e a experiência de formação como centrais nos processos formativos (OLIVEIRA, 2005).

Para Oliveira (2005, p. 54), a poética de formação é possível através da "[...] observância de aspectos que passam despercebidos, tidos talvez como insignificantes, marcados pela fragilidade, ou mesmo, não dantes considerados, no cotidiano das práticas, pelas políticas de formação e pela tradição pedagógica $[\ldots] "$.

Segundo Bondía (2002), o sujeito da experiência não é sujeito da informação, da opinião, do julgar, do fazer, do querer, pois o sujeito da experiência é o sujeito que é similar a um território de passagem, semelhante a uma superfície sensível que aquilo que acontece afeta de alguma forma, deixa alguns vestígios.

Portanto, na caracterização das experiências de formação dos educadores do Assentamento Paulo César Vinha, a abordagem investigativa, que considera os processos formativos, foi centrada nos sujeitos, evidenciando as suas experiências e saberes das experiências.

\section{O percurso metodológico}

Considerando que objetivava realizar um estudo com educadores da modalidade da Educação de Jovens e Adultos no contexto de territórios da reforma agrária do estado do Espírito Santo, realizei inicialmente um levantamento sobre os assentamentos rurais que possuíam escolas com oferta dessa modalidade. Constatei que, em 2014, oito assentamentos rurais do Espírito Santo apresentavam estabelecimentos educacionais que ofertavam essa modalidade de ensino (Quadro 1).

Quadro 1: Escolas das Redes Estaduais e Municipais que ofertam a EJA em Assentamentos Rurais do Estado do Espírito Santo - 2013 


\begin{tabular}{|c|c|c|c|c|}
\hline $\mathbf{N}^{\circ}$ & ESCOLA & ASSENTAMENTO & MUNICÍPIO & $\begin{array}{c}\text { REDE } \\
\text { ESCOLAR }\end{array}$ \\
\hline 1 & EEEF Córrego do Cedro & Paulo Vinha & $\begin{array}{c}\text { Conceição da } \\
\text { Barra }\end{array}$ & Estadual \\
\hline 2 & $\begin{array}{l}\text { EEEF Valdício Barbosa } \\
\text { dos Santos }\end{array}$ & $\begin{array}{c}\text { Valdício Barbosa dos } \\
\text { Santos }\end{array}$ & $\begin{array}{c}\text { Conceição da } \\
\text { Barra }\end{array}$ & Estadual \\
\hline 3 & $\begin{array}{c}\text { EEPEF Saturnino Ribeiro } \\
\text { dos Santos }\end{array}$ & Olinda II & Pinheiros & Estadual \\
\hline 4 & EEEF XIII de Setembro & $\begin{array}{l}\text { Assentamento } \\
\text { Córrego da Areia }\end{array}$ & Jaguaré & Estadual \\
\hline 5 & $\begin{array}{l}\text { EEPEF José Antônio da } \\
\text { Silva Onofre }\end{array}$ & $\begin{array}{c}\text { Assentamento } 13 \text { de } \\
\text { Maio }\end{array}$ & Nova Venécia & Estadual \\
\hline 6 & EEEF Três de Maio & $\begin{array}{c}\text { Assentamento Castro } \\
\text { Alves }\end{array}$ & Pedro Canário & Estadual \\
\hline 7 & $\begin{array}{c}\text { EMPEF lone Azevedo } \\
\text { Campos }\end{array}$ & Assentamento Paraíso & Alegre & Municipal \\
\hline 8 & $\begin{array}{l}\text { EMEIEF Zumbi dos } \\
\text { Palmares }\end{array}$ & $\begin{array}{l}\text { Assentamento Zumbi } \\
\text { dos Palmares }\end{array}$ & São Mateus & Municipal \\
\hline
\end{tabular}

Fonte: Censo Escolar - 2013 - SEDU/GEIA/SEE.

A partir do levantamento inicial, entrei em contato com as referidas unidades escolares, a fim de dialogar sobre a possibilidade da realização da pesquisa com educadores que atuam na modalidade EJA em interface com a modalidade Educação do Campo. Nesse momento, o Assentamento Paulo César Vinha, onde está situada a Escola Córrego do Cedro, mostrou-se como o lócus mais viável para a realização da pesquisa de campo, sobretudo, em virtude da acolhida e do apoio demonstrado por educadores.

Em 2014, a Escola Córrego do Cedro, da rede estadual de ensino, ofertava a modalidade Educação de Jovens e Adultos no $1^{\circ}$ Segmento e no $2^{\circ}$ Segmento do Ensino Fundamental, sendo organizada em módulos semestrais, conforme Quadros 2 e 3.

Quadro 2: Organização do $1^{\circ}$ Segmento do Ensino Fundamental - EJA na Escola Córrego do Cedro - Assentamento Paulo César Vinha

\begin{tabular}{|c|c|c|c|}
\hline Etapa & $\mathbf{N}^{\circ}$ Dias & $\mathbf{N}^{\circ}$ Semanas & $\mathbf{N}^{\circ}$ Horas \\
\hline $1^{\text {a Etapa }}$ & 100 & 20 & 400 \\
\hline $2^{\text {a Etapa }}$ & 100 & 20 & 400 \\
\hline $3^{\text {a Etapa }}$ & 100 & 20 & 400 \\
\hline $4^{\text {a Etapa }}$ & 100 & 20 & 400 \\
\hline
\end{tabular}

Fonte: Projeto Político Pedagógico da Escola Córrego do Cedro, 2014.

Quadro 3: Organização do $2^{\circ}$ Segmento do Ensino Fundamental - EJA - na Escola Córrego do Cedro - Assentamento Paulo César Vinha

\begin{tabular}{|c|c|c|c|}
\hline Etapa & $\mathbf{N}^{\circ}$ Dias & $\mathbf{N}^{\circ}$ Semanas & $\mathbf{N}^{\circ}$ Horas \\
\hline $5^{\text {a Etapa }}$ & 100 & 20 & 400 \\
\hline
\end{tabular}




\begin{tabular}{|c|c|c|c|}
\hline $6^{\text {a }}$ Etapa & 100 & 20 & 400 \\
\hline $7^{\text {a Etapa }}$ & 100 & 20 & 400 \\
\hline $8^{\text {a }}$ Etapa & 100 & 20 & 400 \\
\hline
\end{tabular}

Fonte: Projeto Político Pedagógico da Escola Córrego do Cedro, 2014.

Em 2014, a Escola Córrego do Cedro contou com 9 (nove) educandos matriculados no primeiro segmento do ensino fundamental e 10 (dez) estudantes matriculados no segundo segmento do referido nível de ensino.

Assim, tomando como referência o aporte metodológico da Observação Participante (BRANDÃO, 2007), realizei a pesquisa de campo no Assentamento Paulo César Vinha, situado no Município de Conceição da Barra, na região norte do estado do Espírito Santo (Figura 1).

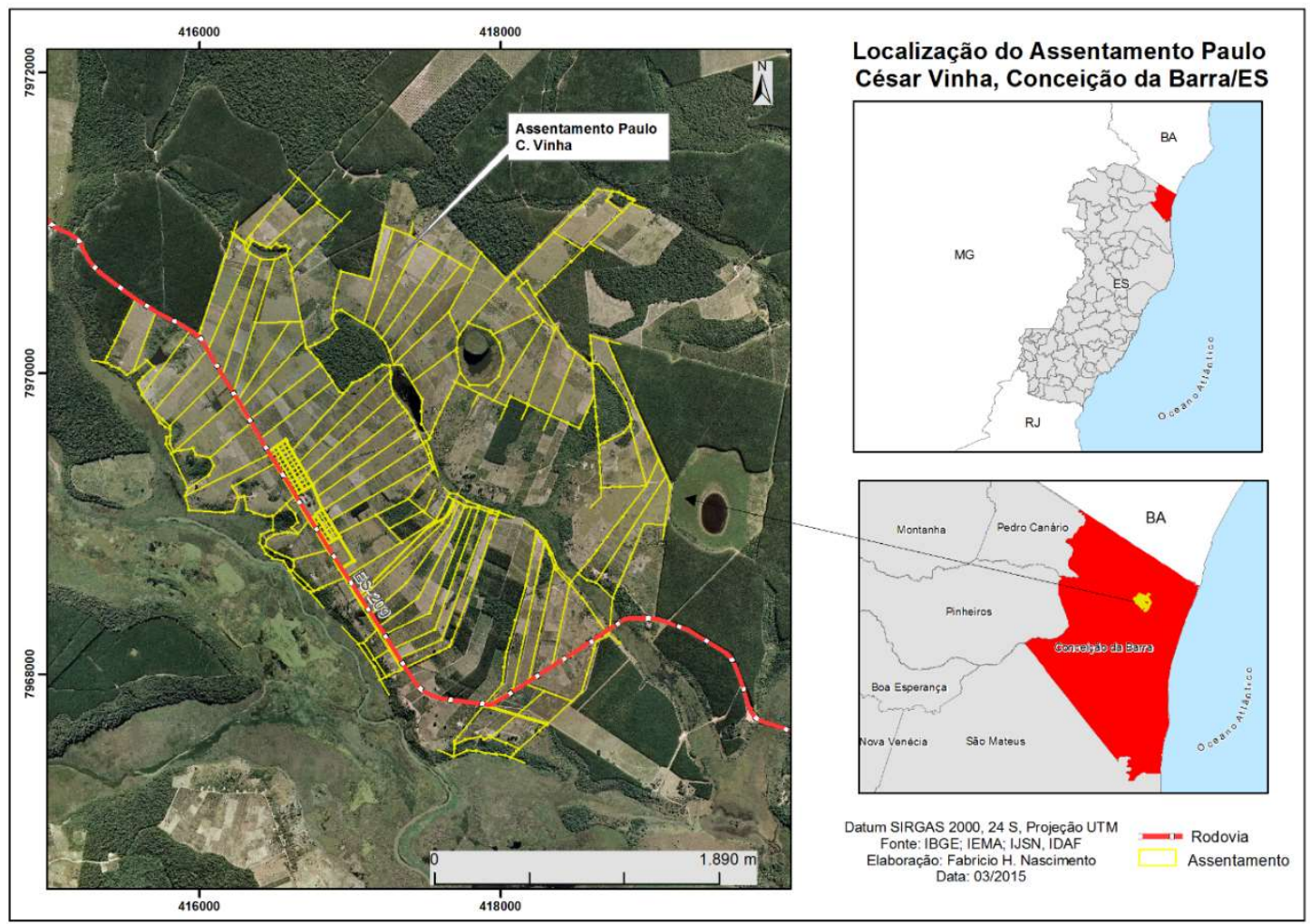

Figura 1: Localização do Assentamento Paulo César Vinha - Conceição da Barra-ES Fonte: IDAF, 1997.

Segundo Brandão (2007), a observação participante consiste na observação que se faz de corpo presente em um determinado lugar, na perspectiva de compreender a sua realidade. Nesse sentido, ser observante consiste em estar em todos os lugares necessários para a coleta de dados, enquanto ser participante está relacionado ao envolvimento com o contexto da 
investigação, com o objetivo de identificação e percepção do meio no qual se está inserido.

O Assentamento Paulo César Vinha foi criado em 5 de dezembro de 1997, após a chegada do acampamento em 1995 na Fazenda Itaúnas, localizada na zona rural do município de Conceição da Barra. As famílias, que vieram de outros municípios do Estado do Espírito Santo, como Vitória, Pinheiros e Pedro Canário, bem como da Bahia e de Minas Gerais, ocuparam as residências existentes nessa Fazenda, passaram a prestar serviços aos proprietários circunvizinhos, além de praticarem a pesca para a subsistência e comercialização no próprio acampamento e no entorno (PROJETO POLÍTICO PEDAGÓGICO, 2014).

Na perspectiva da Observação Participante, a experiência da pesquisa de campo foi se constituindo a partir da realização de entrevistas semiestruturadas e conversas informais com oito educadores que atuaram na modalidade EJA, na Escola Córrego do Cedro, do Assentamento Paulo César vinha, durante o ano de 2014 (Quadro 4).

Quadro 4: Quadro Docente da Educação de Jovens e Adultos na Escola Córrego do Cedro - Assentamento Paulo César Vinha - 2014

\begin{tabular}{|c|c|c|c|}
\hline \multicolumn{4}{|c|}{ Ensino Fundamental ( $1^{\circ}$ Segmento) } \\
\hline $\mathbf{N}^{\circ}$ & Educador(a) & Escolaridade & Disciplina/Nível \\
\hline 01 & Talita & Cursando $6^{\circ}$ período de Pedagogia & Regência de Classe \\
\hline \multicolumn{4}{|c|}{ Ensino Fundamental ( $2^{\circ}$ Segmento) } \\
\hline $\mathbf{N}^{\circ}$ & Educador(a) & Escolaridade & Disciplina/Nível \\
\hline 01 & Lídia & $\begin{array}{l}\text { Pedagogia da Terra; } \\
\text { Cursando Letras / Português; } \\
\text { Especialização em Gestão Integradora. }\end{array}$ & Inglês- $5^{\mathrm{a}}$ e $6^{\mathrm{a}}$ etapas \\
\hline 02 & Moisés & $\begin{array}{l}\text { Pedagogia da Terra; } \\
\text { Licenciatura em Geografia e Educação } \\
\text { Ambiental; Especialização em Psicopedagogia. }\end{array}$ & $\begin{array}{l}\text { Língua Portuguesa e } \\
\text { Matemática }-5^{\mathrm{a}} \text { e } 6^{\mathrm{a}} \\
\text { etapas }\end{array}$ \\
\hline 03 & Débora & $\begin{array}{l}\text { Licenciatura em Pedagogia da Terra; } \\
\text { Especialização em Educação Infantil e Séries } \\
\text { Iniciais. }\end{array}$ & $\begin{array}{l}\text { História- } 5^{\mathrm{a}} \text { e } 6^{\mathrm{a}} \\
\text { etapas }\end{array}$ \\
\hline 04 & Miriã & $\begin{array}{l}\text { Pedagogia da Terra; } \\
\text { Especialização em Psicopedagogia e Docência; } \\
\text { Cursando História. }\end{array}$ & $\begin{array}{l}\text { Geografia- } 5^{\mathrm{a}} \text { e } 6^{\mathrm{a}} \\
\text { etapas }\end{array}$ \\
\hline 05 & Daniel & $\begin{array}{l}\text { Técnico em Agropecuária; } \\
\text { Cursando História. }\end{array}$ & $\begin{array}{l}\text { Agricultura e } \\
\text { Zootecnia }-5^{\mathrm{a}} \text { e } 6^{\mathrm{a}} \\
\text { etapas }\end{array}$ \\
\hline 06 & Maria & $\begin{array}{l}\text { Licenciatura em Pedagogia; } \\
\text { Especialização em Alfabetização e Letramento. }\end{array}$ & $\begin{array}{l}\text { Ciências - } 5^{a} \text { e } 6^{a} \\
\text { etapas }\end{array}$ \\
\hline 07 & Ester & $\begin{array}{l}\text { Licenciatura em Pedagogia; } \\
\text { Especialização em Alfabetização e Letramento. }\end{array}$ & Artes- $5^{\mathrm{a}}$ e $6^{\mathrm{a}}$ Etapa \\
\hline
\end{tabular}


Fonte: Projeto Político Pedagógico da Escola Córrego do Cedro, 2014.

Esses oito educadores atuaram na EJA em regimento de designação temporária no ano de 2014, sendo que 1 (uma) educadora atuou no $1^{\circ}$ Segmento e 7 (sete) educadores atuaram no $2^{\circ}$ Segmento do Ensino Fundamental. Em relação ao grau de escolaridade, 6 (seis) educadores possuíam o nível superior completo, enquanto 2 (dois) estavam cursando o ensino superior em 2014 (PROJETO POLÍTICO PEDAGÓGICO, 2014).

Desse total de educadores ${ }^{1}$, apenas três eram assentados: Ester, Miriã e Talita; quatro estavam na condição de agregados: Lídia, Moisés, Daniel e Débora; enquanto a educadora Maria residia em uma propriedade próxima ao Assentamento Paulo César Vinha.

Após a pesquisa de campo, foram realizadas a sistematização dos dados, através das transcrições de entrevistas e dos registros de conversas informais; e a análise e interpretação dos dados, com ênfase na abordagem das narrativas transcritas, na perspectiva de estabelecer o diálogo entre os resultados obtidos, o problema, o objetivo e o aporte teórico desse estudo.

Em relação à análise e interpretação das narrativas das entrevistas realizadas com os educadores no contexto da observação participante, adotei a postura metodológica de distanciamento dos relatórios lineares e consequentes (CORREAA; SOUZA, 2016), objetivando a problematização de relatos autobiográficos idealizados, com base no seguinte pressuposto de Bourdieu (2006, p.188): "tudo leva a crer que o relato de vida tende a aproximar-se do modelo oficial da apresentação oficial de si, carteira de identidade, ficha de estado civil, curriculum vitae, biografia oficial [...]".

Além disso, adotei uma atitude de "estranhamento" na interlocução com os educadores com o intuito de superação de uma visão romântica. Nesse sentido, no decorrer da pesquisa realizei reflexões sobre o que eu compreendia e o que eu pensava que compreendia, assumindo também a posição de pesquisador que ignora o que sabe, considerando que anteriormente havia vivenciado experiências de envolvimento e identificação com o MST. De acordo

\footnotetext{
1 Todos os participantes da pesquisa assinaram o Termo de Consentimento Livre e Esclarecido. Apesar disso, optei por utilizar nomes fictícios.
} 
com Cunha e Röwer (2014, p.28), “O estranhamento não é somente do outro, mas também de si. O espanto acontece em situações que vivenciamos e diante de nossas próprias atitudes [...]". Em outra dimensão investigativa, também busquei não induzir as respostas dos sujeitos, durante a realização das entrevistas e conversas informais, pois percebia em alguns momentos que os sujeitos da pesquisa pensavam que eu estava esperando respostas "prontas".

\section{As experiências de formação de educadores do Assentamento Paulo César Vinha}

Conforme apresentado no tópico anterior, todos os educadores já vivenciaram ou estão vivenciando a formação inicial docente, em nível superior. Além disso, eles já estão vivenciando processos formativos contínuos no exercício profissional docente em suas respectivas áreas de atuação, inclusive os que ainda não concluíram a graduação.

No entanto, destaco que a abordagem do presente estudo leva em consideração a concepção ampla de formação (OLIVEIRA, 2005), que não se restringe à formação inicial e continuada. Assim, a análise das experiências formativas dos educadores não se restringe às experiências vividas no início da formação docente, mas se estende para outros processos vivenciados ao longo de suas vidas.

Em outra dimensão, ressalto que não concebo as experiências dos educadores como sinônimo de experiência profissional. Não desconsidero a dimensão formativa do exercício profissional docente, mas concebo a experiência para além do trabalho. Segundo Bondía (2002),

[...] às vezes se confunde experiência com trabalho. Existe um clichê segundo o qual nos livros e nos centros de ensino se aprende a teoria, o saber que vem dos livros e das palavras, e no trabalho se adquire a experiência, o saber que vem do fazer ou da prática, como se diz atualmente. Quando se redige o currículo, distingue-se formação acadêmica e experiência de trabalho. (p.23).

Portanto, se por um lado, não restrinjo as experiências dos educadores à formação inicial e continuada, por outro lado, também não considero a 
concepção restrita de experiência ao tempo de exercício da atividade profissional docente.

Contrapondo-me a essas concepções reducionistas da experiência e da formação, reafirmo a concepção ampla de formação. A partir dessa perspectiva e considerando os referenciais teórico-metodológicos adotados, caracterizei as experiências comunicáveis de formação de educadores de jovens e adultos do Assentamento Paulo César Vinha.

\section{Os educadores e o declínio das experiências}

A partir da realização da pesquisa no contexto do Assentamento Paulo César Vinha, evidenciou-se que as experiências de formação dos educadores, compreendidas como experiências comunicáveis (BENJAMIN, 1994), estão em declínio e, consequentemente, a arte de narrar também está enfraquecida.

Além desse processo evidenciado pelo estudo, que demonstra a atualidade do pensamento de Walter Benjamin, constatou-se também as causas fundamentais da pobreza de experiência e da limitação da faculdade de intercambiar experiências apresentadas pelos educadores: o acesso restrito à fonte narrativa, ou seja, à experiência que passa de pessoa a pessoa; e o caráter desmoralizador das próprias experiências vividas por esses sujeitos.

Considerando que a experiência transmitida de pessoa para pessoa é a fonte recorrida pelos narradores, concebe-se que os mais velhos, como os pais, possuem papel fundamental na transmissão de experiências para os jovens (BENJAMIN, 1994). Desse modo, na interlocução com educadores do Assentamento Paulo César Vinha, percebi que os mesmos tiveram acesso restrito às experiências compartilhadas, em virtude da dificuldade de seus pais em narrar e transmitir experiências. Ao buscar compreender essa capacidade limitada dos pais em intercambiar experiências, constatei que as principais causas estão associadas, sobretudo, às suas experiências dramáticas de alienação com a terra, carências socioeconômicas e luta pela terra, como podemos observar a seguir: 
Educadora Ester: "Os meus pais nunca tiveram terra, sempre o meu pai trabalhou de diarista, de meeiro, nunca tiveram uma oportunidade de ter uma terra."

Educadora Maria: "Foi muito difícil, muito complicado, onde sobreviviam da caça e da pesca, era muito difícil mesmo, a minha mãe era muito sofredora, o meu pai fazia de tudo para não faltar as coisas em casa."

Educadora Débora: "Meu pai na época trabalhava, ele era vigia de uma empresa e aí o grupo de militantes do movimento reuniu a comunidade pra estar montando um acampamento nessa região, na época minha mãe não queria ir, nós éramos todos muito pequenos, ela estava grávida e meu pai foi sozinho, largou emprego e foi acampar, aí ele ficou eu acho uns dois meses mais ou menos acampado sozinho; nós, eu, minha mãe e meus irmãos, ficamos lá no Km 13, aí depois ele veio cá, buscou a gente, nós fomos, aí nós ficamos acampados a princípio lá no $\mathrm{Km} 35$, aí depois, mais ou menos dois meses depois, nós fomos para o $\mathrm{Km} \mathrm{41,} \mathrm{aí} \mathrm{cinco} \mathrm{meses} \mathrm{que} \mathrm{a} \mathrm{gente} \mathrm{estava} \mathrm{acampados}$ saiu a posse da terra, aí nós fomos pra Ecoporanga, isso eu tinha oito anos na época."

A partir dessas narrativas, constata-se que as experiências desmoralizadoras vividas pelos pais dos educadores, num contexto de concentração fundiária de caráter capitalista no território brasileiro e consequente proletarização, tornaram os mesmos pobres em experiências comunicáveis, quase privados da faculdade da arte de narrar, com capacidade limitada no compartilhamento de sabedoria, conselhos e ensinamentos.

Em outra dimensão, evidencia-se que o acesso restrito dos educadores à fonte narrativa está relacionado também à perda das tradições, que por sua vez está conectada às problemáticas socioeconômicas que afetam os camponeses.

Além disso, constatei que a pobreza de experiências dos educadores também se vincula às próprias experiências dramáticas vividas por eles na infância, que se caracterizaram como vivências, na perspectiva de Walter Benjamin (1989), ou seja, "experiências" vividas pelo indivíduo solitário, conforme podemos perceber a seguir: 
Educador Daniel: "A minha infância não foi muito aquela infância que toda a criança quer ter, foi um pouco assim, era trabalhoso, sempre tinha tarefa pra executar, então brincadeiras era poucas, brincadeiras, quando chegava, tinha brincadeira quando eu ia pra casa da minha mãe em Pedro Canário, vídeo game, começou a aparecer, aí tinha os coleguinhas que brincava de bola na rua, às vezes eu ia pra sede lá nessa fazenda, ia pra sede pra jogar bola com os meninos então foi um pouco misturado com trabalho mesmo, trabalhava, tinha as atividades, então era pouca atividade assim de brincadeira."

Educadora Débora: "Olha, a minha infância assim, eu não lembro muito, eu lembro que a gente trabalhava muito, nós éramos muito felizes também, muitos irmãos, a gente sempre brincava, mas eu lembro que as responsabilidades de adulto já foi nos apresentada muito cedo, nós éramos em muitos irmãos, então os mais velhos cuidavam dos mais novos, então a gente já ia assumindo essa responsabilidade de cuidar da casa, meu pai pegava empreitada, logo quando formou o assentamento 22 de Julho, onde os meus pais moram até hoje na região de Ecoporanga, como no início de assentamento não se produzia muita coisa aí o meu pai pegava empreitada nas fazendas vizinhas e a gente sempre ajudava capinando, plantando, então eu lembro assim que a gente trabalhava muito."

Apesar dos relatos dos educadores evidenciarem a transmissão de saberes das experiências dos pais, através do trabalho na lavoura, percebe-se que o tempo da infância foi o tempo destinado predominantemente para o trabalho, que implicou no esvaziamento do tempo do brincar. Nesse sentido, o excesso de trabalho e a falta de tempo, considerados por Bondía (2002) como inimigos da experiência, limitaram as experiências desses educadores na infância.

\section{Os educadores e as raras experiências}

O estudo revelou também que, apesar de se tornarem cada vez mais raras, as experiências de formação dos educadores não desapareceram completamente, em razão da existência das seguintes condições para a sua existência no contexto do Assentamento Paulo César Vinha: as experiências 
transmitidas na infância; a presença de um grupo de educadores sedentários e de um grupo de educadores viajantes (migrantes); e a constituição de uma comunidade de experiências na educação de jovens e adultos.

Dessa forma, em relação às experiências transmitidas e vividas na infância, os educadores do Assentamento Paulo César Vinha relataram:

Educadora Ester: "Bom, momentos tristes eu não tive não, mas muito felizes eu tive, foi a questão da minha mãe falar assim, você vai ter que estudar, mas você tem também que brincar, não vou tirar a sua liberdade de brincar, então assim ao mesmo tempo que ela falava assim você vai ter que estudar, ter compromisso nas tarefas de casa e depois você pode brincar, então nisso ela deu liberdade pra mim, então hoje se eu tenho uma infância boa também dedico à minha mãe, ela soube dividir esses espaços, não me colocava pra trabalhar."

Educadora Débora: "Eu lembro com saudade, na verdade porque nós éramos muitos, então a gente brincava muito, depois na adolescência também a gente sempre reunia e brincava, brincadeiras saudáveis, brincadeiras que eu cultivo e tento passar para as minhas filhas."

Educador Moisés: "Foi um período muito bom, desde quando eu fui pra lá, a gente morava na roça, meu pai sempre aprendendo a lidar com a terra, aqueles valores da família, do trabalho, eu aprendi muito, devo muito aos meus pais isso aí o que eu aprendi enquanto pessoa, a própria formação da personalidade foi um trabalho que os meus pais fizeram, os valores humanos que eu aprendi dentro de casa."

Educadora Lídia: "Ele orientava sobre a lua, a lua, eu aprendi praticamente essa experiência mais com a família do que na escola, porque a escola dá conta do científico, de falar da questão das fases da lua, mais nessa questão científica, mas em saber, em mostrar, apontar logo, vai vir a lua tal, aí contava lá nos dedos que era de sete em sete dias, se eu não me engano, aí ele apresentava a próxima lua que estava se aproximando e daí também na roça, ele fazia a mesma coisa, olha a gente vai começar a limpar a terra porque vai vir a lua tal que é pra plantar o feijão ou pra plantar mandioca, senão se plantar em outra lua vai encher de lagarta, vai ser assim." 
Educadora Maria: "Eu me lembro, nunca me esqueço da minha avó, de todas as vezes que era semana santa, que ela morava, a gente morava na parte de cima, era a parte que eu mais gostava da minha infância, na semana santa, onde ela nos recebia com todo o carinho do mundo, aquela mesinha velha, antiga, onde a gente dormia lá na esteira no chão, ela dormia na esteira e dava a cama pra gente, ela dormia na pior parte que era o colchão da esteira e dava cama pra gente e ali ela recebia a gente com tudo o que era tipo de coisa, pratos, aqueles muchás, coisas, da minha infância, a melhor parte de minha infância que eu lembro, a melhor parte é essa, onde ali a gente pescava no brejo ali, passava o dia ali com ela, dormia ali."

Nesses relatos, evidencia-se que os educadores mencionam os valores, tradições e ensinamentos transmitidos pelos seus pais e avós na infância. Além disso, a educadora Débora menciona que tenta ensinar as brincadeiras tradicionais para as suas filhas, ou seja, busca transmitir experiências para os mais jovens no contexto atual.

Considerando a teorização de Benjamin (1989), constatei também na observação participante com educadores do Assentamento Paulo César Vinha uma das condições para a existência do narrador: a existência de um grupo de sedentários e de um grupo de viajantes.

Os educadores que não apresentam experiências intensas de migração, uma vez que moraram a maior parte de suas vidas nessa região da comunidade do Assentamento Paulo César Vinha, exemplificando o grupo de sedentários. Nesse grupo, encontramos os seguintes educadores: Ester, Talita, Lídia, Daniel e Maria. A educadora Lídia, por exemplo, que vivia nessa região antes da chegada do MST, narra a história de constituição do Assentamento Paulo César Vinha, enquanto o educador Daniel narra a importância da experiência vivida exclusivamente no interior:

Educadora Lídia: "O que a gente sabia, o que eu sabia é que a fazenda estava à venda e que já tinha uma negociação com o INCRA, que já existia essa negociação, então só que as coisas surgiram, aconteceram de forma que não foi uma coisa assim já pré-estabelecida, que ia acontecer, de repente aconteceu a ocupação, primeira ocupação no Valdice, no Valdice a terra não deu conta de 
ocupar todas as famílias, se acamparam numa região próximo à fazenda, às margens de um córrego próximo à fazenda, então dali, desse córrego, aí já logo liberou pra ocupar a fazenda, essas pessoas que estavam acampadas na margem desse córrego próximo já entraram pra dentro da fazenda, já entraram e assim, outras familias também chegaram no mesmo momento, nesse período se totalizou mais de trezentas famílias acampadas, então foi o acampamento se estendeu na sede da fazenda, todinha era acampamento, então assim foi um aglomerado de pessoas muito grande naquele momento, então assim pra comunidade foi uma surpresa aquilo, foi novo".

Educador Daniel: "Eu sempre morei no interior e no interior a gente tem esse contato com a natureza, quintal grande que não oferece perigo, os vizinhos todos amigos, então a gente era muito livre mesmo".

Por outro lado, o grupo de viajantes é exemplificado pelos educadores que apresentaram experiências intensas de migração em suas "trajetórias" de vida. Nesse segundo grupo, encontramos os educadores Moisés, Débora e Miriã. Os relatos a seguir evidenciam experiências migratórias desses educadores:

Educador Moisés: "Tenho boas recordações, amigos que eu fiz nessa época que são meus amigos até hoje toda vez que eu vou lá na Bahia, todo final de ano eu vou e faço questão de reencontrar com essas pessoas, onde nós lembramos desses períodos damos risadas de coisas boas [...] eu me sinto parte de lá, na verdade eu nasci em São Paulo por acaso porque os meus pais foram pra lá, mas eu não me sinto paulista, eu me sinto baiano, a minha origem é baiana porque o meu pai e a minha mãe eram todos baianos e eles estavam em São Paulo quando eu nasci, não significa que eu sou paulista”.

Educadora Débora: "Meus tios moram lá ainda, eu fui lá o ano passado, vou sempre, eu passo lá quando eu vou pra casa dos meus pais porque é na beira da BR, mas eu vejo que o lugar em si desenvolveu pouco, isso tem 25 anos atrás, a comunidade já tem uns trinta anos e assim muito carente, as casas muito carentes, muito precárias, não tem o posto de saúde, a comunidade é dependente de água vinda de carro pipa, então eu acredito que se a gente tivesse morando lá até hoje a gente não teria avançado muita coisa não porque 
pelo menos $80 \%$ das famílias que moram lá até hoje não conseguiram progredir então é vejo na época a gente acampou, assentou e tudo como uma oportunidade de crescimento financeiro, pessoal mesmo".

Educadora Miriã: "Nasci em Vitória, mas eu falo que eu sou veneciana porque passei a minha vida toda lá em Nova Venécia [...] Vou, mas é muito difícil porque é distante daqui a Nova Venécia e eu trabalho com meu marido porque ele trabalha com, além dele ser agricultor, ele também trabalha com transporte escolar, ele que leva os alunos, ele que pega os alunos daqui da redondeza e leva pra escola, então ele trabalha aqui e em Dunas, Itaúnas, ele leva o Ensino Médio, ele leva daqui pro Ensino Médio lá, então a vida dele é corrida, uma hora ele está aqui, outra hora ele está lá em tal lugar, ele é um dos coordenadores do Assentamento também, então não é todo o dia que ele pode estar andando, eu passo seis, tem vez que eu passo seis, sete meses sem ir à casa da minha mãe, eu falo com minha mãe todo dia pelo telefone".

Além das narrativas compartilhadas, destaco que a atuação dos educadores na modalidade da Educação de Jovens e Adultos proporciona condições para a escuta de narrativas de experiências dos educandos, sobretudo, através da contação de histórias, conforme podemos observar nos relatos seguintes:

Educador Moisés: “Eu tenho gostado muito, eu tenho me identificado muito com a EJA porque eu assim nunca tinha trabalhado assim de forma direta com eles e assim você aprende, eu aprendo, eu costumo dizer, tem hora que a gente aprende mais do que você leva pra eles, mais do que ensina, você aprende o que? Você aprende a vivência no dia a dia, valores que não têm preços, coisas assim do dia a dia que você [...] eles contam a história de vida deles então às vezes a gente para a aula e conversa, eles contam, isso é construção de conhecimento, tanto pra eles quanto pra mim, eles socializam o que cada um passou, o que foi a vida de cada um e aí socializam, criam aquele debate na sala de aula e isso tem sido muito maravilhoso no meu trabalho, gratificante profissionalmente falando".

Educadora Talita: "Na sala de aula, eles falam da história de vida deles, como era antigamente pra hoje a diferença, eles contam as histórias deles igual 
essa semana mesmo eu estudei como eles São João como que era antigamente como que é hoje e assim eles contam cada história assim diferente tem umas diferenças assim nossa mas é muito engraçado, estou adorando a EJA".

Educadora Miriã: "Tem muita, trajetória de vida deles, assim têm muitos que é marcante, entendeu? Tem muitas pessoas que já sofreram muito pra chegar onde chegou até hoje, entendeu? Igual esse senhor que eu falei, Senhor Josias, finado Josias, ele foi para o acampamento, ele era casado, a mulher não foi junto com ele, a mulher falou que se ele quisesse que ele fosse sozinho, ele foi sozinho, a mulher não veio com ele aqui, ele contando tudo, a mulher não veio, ele morou sozinho, nem filho e nem a mulher dele não veio, ele ficou naquela casinha dele ali, sozinho, mas ele não desistiu da terra".

Dessa forma, esses educadores possuem uma posição privilegiada no contexto do Assentamento Paulo Cesar, uma vez que além do acesso às experiências de seus pais e das experiências vividas em suas "trajetórias" de vida, eles também intercambiam experiências com os educandos da EJA. Nesse sentido, diferentemente da vivência do indivíduo isolado, os educandos e educadores da EJA constituem uma comunidade de experiências nesse território da reforma agrária.

Nesse sentido, evidencia-se a existência de uma comunidade tradicional no Assentamento Paulo César Vinha, que funda a dimensão prática da narrativa tradicional, e que vem se tornando cada vez mais rara na sociedade capitalista moderna.

\section{Considerações Finais}

Considerando a concepção ampla de formação, que compreende o sujeito da experiência e a experiência de formação como centrais nos processos formativos, e a perspectiva de superação de abordagens centradas na ausência ou carência desses processos formativos nas práticas docentes desenvolvidas nas modalidades da educação de jovens e adultos e da educação do campo, o presente estudo caracterizou as dimensões das experiências formativas dos educadores do Assentamento Paulo César Vinha, valorizando as suas "trajetórias" de vida em interface com a atuação docente nessas modalidades. 
Assim, o presente estudo revelou basicamente duas dimensões das experiências dos educadores do Assentamento Paulo César Vinha. Na primeira dimensão, caracterizada pelo declínio das experiências, evidenciou-se que as causas consistem no acesso restrito à fonte narrativa e no caráter desmoralizador das experiências vividas, como o excesso de trabalho e a falta de tempo. Já a segunda faceta é caracterizada pelas experiências raras dos educadores, evidenciadas nas experiências vividas na infância, bem como nas experiências dos migrantes e sedentários e na constituição de uma rara comunidade de experiências com os educandos da Educação de Jovens e Adultos.

Desse modo, os resultados dessa investigação evidenciam que as causas do enfraquecimento das experiências dos educadores, como o excesso de trabalho e a falta de tempo, constituem demandas formativas que precisam ser consideradas e valorizadas nos processos de formação docente.

Além disso, o presente estudo também apresenta possibilidades de constituição e de fortalecimento de momentos de compartilhamento e intercambiamento de experiências e saberes das experiências dos educadores nas políticas e práticas de formação docente.

\section{Referências}

BENJAMIN, Walter. Charles Baudelaire: um lírico no auge do capitalismo. 1. ed. São Paulo: Brasiliense, 1989. (Obras Escolhidas; v. 3).

Escolhidas; v.1).

Magia e técnica, arte e política. São Paulo: Brasiliense, 1994. (Obras

BONDÍA, Jorge Larrosa. Notas sobre a experiência e o saber de experiência. Tradução: João Wanderley Gerald. Revista Brasileira de Educação. N.19, jan./abr., 2002, $\quad$ p. 20-28. Disponível em: <https://www.scielo.br/pdf/rbedu/n19/n19a02.pdf>. Acesso em: 15 jul. 2020.

BOURDIEU, Pierre. A ilusão biográfica. In: FERREIRA, Marieta de Moraes; AMADO, Janaina. (Orgs.). Usos e abusos da história oral. 8. ed. Rio de Janeiro: FGV, 2006. p.183-191.

BRANDÃO, Carlos Rodrigues. Reflexões sobre como fazer trabalho de campo. Sociedade e Cultura, v. 10, n.1, p. 11-27, 2007. Disponível em: $<$ https://www.revistas.ufg.br/fcs/article/view/1719/2127>. Acesso em: 01 jul. 2020. 
CORREAA, Carolina Salomão; SOUZA, Solange Jobim e. Walter Benjamin e o problema do texto na escrita acadêmica. Mnemosine, v. 12, n.2, p. 2-25, 2016. Disponível em: $<$ https://www.epublicacoes.uerj.br/index.php/mnemosine/article/view/41651/pdf_360>. Acesso em: 25 out. 2020.

CUNHA, Jorge Luiz da; RÖWER, Joana Elisa. Ensinar o que não sabe: estranhar e desnaturalizar em relatos (auto)biográficos. Santa Maria, v. 39, n. 1, p. 27-38, jan./abr. 2014.28 p. $28 . \quad$ Disponível em: $<$ https://periodicos.ufsm.br/reveducacao/article/view/11340>. Acesso em: 10 jul. 2020.

GONÇALVES, Max Alexandre. Relampejos em Walter Benjamin: ideias e reminiscências sobre o brinquedo. In: MACHADO, Carlos Eduardo Jordão; MACHADO Jr., Rubens; VEDDA, Miguel. (Orgs.). Walter Benjamin: experiência história e imagens dialéticas. 1. ed. São Paulo: Editora Unesp, 2015.

KONDER, Leandro. Walter Benjamin: o marxismo da melancolia. 3. ed. Rio de Janeiro: Civilização Brasileira, 1999.

OLIVEIRA, Edna Castro de. Os Processos de Formação na Educação de Jovens e Adultos: A "panha" dos girassóis na experiência do PRONERA MST/ES. 172 f. 2005. Tese (Doutorado em Educação) - Programa de PósGraduação em Educação da Universidade Federal Fluminense, Rio de Janeiro, 2005.

ORLANTE, Emiliano; SALINAS, Martín. Notas sobre a significação da obra de Kafka no desenvolvimento do pensamento estético de Walter Benjamin. In: MACHADO, Carlos Eduardo Jordão; MACHADO Jr., Rubens; VEDDA, Miguel. (Orgs.). Walter Benjamin: experiência histórica e imagens dialéticas. 1. ed. São Paulo: Editora Unesp, 2015.

PROJETO POLÍTICO PEDAGÓGICO. Escola Estadual de Ensino Fundamental Córrego do Cedro, Conceição da Barra-ES, 2014.

\section{Sobre o autor}

\section{Júlio de Souza Santos}

julio.santos@ifes.edu.br

Doutor em Educação (2015) e Mestre em Educação (2010) pelo Programa de Pós-Graduação em Educação da Universidade Federal do Espírito Santo (UFES). Licenciado em Geografia (2006) e Bacharel em Geografia (2008) pela UFES. Professor do Ensino Básico, Técnico e Tecnológico do Instituto Federal do Espírito Santo (IFES), campus Vitória, onde leciona em cursos técnicos integrados ao ensino médio na modalidade de educação de jovens e adultos (Proeja). Membro do Grupo de Pesquisa (CNPq) Culturas, Parcerias e Educação do Campo e do Grupo de Pesquisa (CNPq) Educação e Cidadania. 